\title{
Editorial
}

Public Health
Genomics
Public Health Genomics 2018;21:164-167

DOI: $10.1159 / 000499051$
Received: February 18, 2019

Accepted: February 18, 2019

Published online: April 18, 2019

\section{Editorial Commentary on "Psychological Impact of Learning CDKN2A Variant Status as a Genetic Research Result" by Zhu et al.}

\author{
Neil A. Holtzman ${ }^{\text {a }}$ Nicole Probst-Hensch ${ }^{\text {b, } c}$ \\ ${ }^{a}$ The Johns Hopkins University School of Medicine, Baltimore, MD, USA; ${ }^{b}$ Swiss Tropical and Public Health Institute \\ Swiss TPH, Basel, Switzerland; ' University of Basel, Basel, Switzerland
}

Progress in sequencing individual genomes has expanded the ability to predict risks of disease in the person being tested or in their biological relatives. The risk, but not necessarily age of onset or severity, can be precisely quantified for Mendelian disorders in which the presence of a single disease-related mutation in double gene dosage (recessive disorders) or in single gene dosage (dominant and X-linked disorders) has been detected. For the vast majority of disorders in which inheritance plays a role, the prediction is less precise; the presence of specific mutations at gene loci, other than the one being examined, and/or environmental factors must be present for the disease to manifest. These modifiers also influence the age of disease onset and how the disease presents. Progress has been much slower in identifying such secondary factors in order to improve the predictability of tests for single mutations.

For a handful of non-Mendelian conditions, including hereditary types of breast (BrCa 1,2) and colon (HNPCC, FAP) cancer, genetic testing for mutations of known clinical significance is sufficiently predictable to be clinically available to high-risk families. In this issue, Zhu et al. [1] examine behavioral consequences of informing apparently healthy research subjects of the results of a test for the presence of the L16R c.47T $>\mathrm{G}$ (p.Leu16Arg) variant in the CDKN2A gene, while its association with pancre-

\section{KARGER}

(c) 2019 S. Karger AG, Basel

E-Mail karger@karger.com

www.karger.com/phg atic cancer (PC) is still under investigation. Although it accounts for only $3 \%$ of all new cancer cases in the USA, PC accounts for $7 \%$ of all cancer deaths, and it has a 5-year survival rate of only $8.5 \%$ [2]. Hereditary forms account for $5-10 \%$ of all pancreatic cancers $[2,3]$.

Several sources, cited by Zhu et al. [1], have published criteria for returning individual genetic research results (IRR). A duty to inform "is met," Beskow and Burke write, "when, in the course of research, an investigator discovers genetic information that clearly indicates a high probability of a serious condition for which an effective intervention is readily available" [4]. The Clinical Sequencing Exploratory Research (CSER) Consortium and the Electronic Medical Records and Genomics (eMERGE) Network recommend that "at a minimum, researchers should offer individual genomic research results that are valid, medically important, and actionable if discovered purposefully or by chance during the course of data analysis" [5]. Similar guidelines have been published by a National Heart, Lung, and Blood working group [6].

Zhu et al. [1] report that returning IRR is "often motivated by feelings of obligation that the genetic information may be valuable to participants..." Yet the paper they cite in support of this statement notes, "designing research with disclosure of individual genetic results as an integral component is a morally optional choice, not an 
Table 1. Cumulative risk of PC in papers cited by Zhu et al. [1]

\begin{tabular}{|c|c|c|c|}
\hline $\begin{array}{l}\text { Reference } \\
\text { (as in Zhu et al.) }\end{array}$ & Type of risk conferred by germ-line mutation & $\begin{array}{l}\text { Reported risk, } \\
\%(95 \% \mathrm{CI})\end{array}$ & Comment \\
\hline McWilliams [20], 2011 & $\begin{array}{l}\text { Cumulative risk of PC by age } 80 \text { in CDKN2A } \\
\text { carriers }\end{array}$ & $57.6(7.9,85.7)$ & $\begin{array}{l}n=1,537 ; \text { non-Hispanic white; } \\
4 \text { CDKN2A exons sequenced; } \\
\text { Increased risk limited to smokers }\end{array}$ \\
\hline de Snoo [25], 2008 & $\begin{array}{l}\text { Cumulative risk of PC by age } 80 \text { in p16-Leiden } \\
\text { (CDKN2A variant); } \\
\text { Relative risk of PC }\end{array}$ & $\begin{array}{l}19-42 \text { (range of } \\
\text { estimates) } \\
46.6(24.7-76.4)\end{array}$ & $\begin{array}{l}n=606 \text { tested in } 22 \text { melanoma } \\
\text { families with CDKN2A founder } \\
\text { mutation (p16-Leiden) }\end{array}$ \\
\hline Vasen [26], 2016 & $\begin{array}{l}\text { Cumulative risk by age } 70 \text { in p16-Leiden and } \\
\text { one with c. } 67 \mathrm{G}>\mathrm{C}, \mathrm{G} 23 \mathrm{R}\end{array}$ & 14 (not reported) & $\begin{array}{l}n=178 \text { carriers; } 13 \text { detected with } \\
\text { PC by EUS or MRI; } \\
5 \text {-year survival rate is } 24 \%\end{array}$ \\
\hline Begg [27], 2005 & Cumulative risk of melanoma by age 80 & $28(18,40)$ & $n=3,550 ;$ population based \\
\hline
\end{tabular}

obligation..." [3]. Moreover "feelings" may get in the way of looking at data objectively, and in this paper, Zhu et al. [1] have let their feelings get the better of them; they have misled readers, their Institutional Review Board, and their research subjects by not fulfilling the criteria for returning IRR that have been promulgated. We hope this editorial will inform all authors of the rigorous criteria they must establish before Public Health Genomics, and we hope other journals, will accept papers regarding the return of genetic research results to individual subjects in the future.

Zhu et al. [1] base their offering of IRR on 4 factors: (1) the pathogenicity of the $C D K N 2 A$ variant; (2) the validity of the test for the CDKN2A variant; (3) the action(s) that can be taken if the mutation is present; and (4) the decision of the principal investigator. Regarding this last factor, the authors write, "the specific context of this research wherein results could have particular importance for families who experience a high burden of cancer led the principal investigator (G.M.P.) to disclose the status of the CDKN2A variant, positive or negative, as IRR to participants who wanted to know." No acknowledgment is given to others, such as bioethicists, who might have been consulted before the principal investigator made this decision. On the strength of the evidence regarding factors (1), (2), and (3), this decision was unwarranted.

Zhu et al. [1] maintain that the p.Leu16Arg variant "is likely pathogenic, and it is currently classified as pathogenic/likely pathogenic in ClinVar." They cite 4 references in support of its pathogenicity [3,7-9]. One reference
[3] is probably the parent study of which Zhu et al.'s is a part; the author list includes two authors of the paper under discussion, and the study comes from the same institution. It reports that $C D K N 2 A$ germline mutations occurred significantly more frequently in PC patients than in controls drawn from public sequencing data, but it concluded "the study did not have sufficient information to estimate lifetime probability of cancer (penetrance) in carriers of the predisposition gene mutations" [3]. One of their other citations lists the c.47T $>\mathrm{G}$ (p.Leu16Arg) CDKN2A mutation as pathogenic for hereditary melano$\mathrm{ma}$ and "hereditary cancer-predisposing syndrome" but does not specify PC [7]. The third reference was not accessible to us [8]. We will discuss their fourth citation, McWilliams et al. [9], below.

Establishing the pathogenicity of a mutation is not tantamount to saying that everyone who possesses it will get the disease, or cancer, in question. It is the penetrance of the mutation - the chance that a person, e.g., with the CDKN2A variant, will develop PC over their lifetime that is important for establishing the validity of testing for the mutation. Zhu et al. [1] tell their subjects "that if the IRR is confirmed in a CLIA-certified lab, their lifetime risk for PC could be up to $60-70 \%$ and lifetime risk for melanoma could be up to $30-40 \%$." We could not substantiate this statement when we examined the 5 references they cite as evidence [9-13] (see Table 1). Cumulative risks to 70 or 80 years ranged from 14 to $58 \%$ and were estimated with considerable uncertainty as evidenced by the wide confidence intervals. One of the cita- 
tions was for risk of melanoma not PC [11]. In the Mayo Clinic study [9], the cumulative risk of $58 \%$ was almost entirely due to the cumulative risk (to age 80 ) in smokers (92.7\%); while it was only $2.1 \%$ in non-smokers. Zhu et al. [1] note that smoking cessation is one of the National Cancer Institute's cancer prevention guidelines and is recommended in their counseling to non-carriers as well as, presumably to, carriers. Telling smokers that they have a mutation that makes it more likely they will develop cancer or other smoking-related diseases does not necessarily alter their smoking habits [14].

The low and variable cumulative risks render CDKN2A testing possibly harmful to the research subjects who test positive but will not develop PC. How will the mental health of both false positives and true positives be affected by learning that they are at increased risk for a cancer that has a 5-year survival of $8.5 \%$ ? Zhu et al.'s data, from only 15 carriers, does not provide reassurance [1]. In the 6 months of follow-up, some of them demonstrated disappointment, anxiety, and worry.

Let us consider actionability. In the current guidelines for the management of PC, the authors tell us, "asymptomatic individuals with a genetic predisposition are recommended to undergo surveillance for PC with endoscopic ultrasound and/or magnetic resonance imaging of the pancreas." They cite 3 references [15-17], 2 of which stress that surveillance should be conducted within research protocols $[15,16]$.

In a recent retrospective study, to which Zhu et al. [1] had access but did not cite (see Table 1), not one of the 23 out of 87 patients carrying an inherited mutation associated with an increased risk of PC who underwent endoscopic ultrasound, magnetic resonance imaging, or computed tomography, and were found to have an abnormality, developed PC on follow-up of 21.7-43.5 months [18]. Patients with CDKN2A variants were not included in DaVee et al.'s study [18]. In an accompanying editorial, Bruno [12] (who is cited by Zhu et al. [1] for another reason [see Table 1]) points out that pancreatic abnormalities of the type seen by DaVee et al. [18] are found in patients without genetic predispositions, and without $\mathrm{PC}$, at higher frequency than those reported in carriers by DaVee et al. Bruno concludes, "(A)s long as there is no proof of benefit and there is the potential of harm, [surveillance] for pancreatic cancer should not be undertaken outside a research program" [12]. We do not know whether the findings would have been different had patients with the CDKN2A variant been included in DaVee et al.'s study [18].

Zhu et al. [1] recommend that subjects found to carry the CDKN2A variant in the research lab, "follow-up with their physician and repeat the genetic test in a clinical [CLIA-certified] lab." If the research result is confirmed, presumably it would be up to their physicians to decide on surveillance and further follow-up. Such referrals might remove subjects from further systematic research, delaying the acquisition of data.

We return to the matter of feelings - this time the feelings of the research subjects. It was after all, their feelings that this study was about, "how learning specific CDKN2A variant status may influence individuals' general self-rated health, quality of life (QoL), emotional experiences, and genetic testing-related concerns." In designing the study, did the researchers ever define a sufficient level of harm to terminate the study, i.e., to stop returning genetic research results to the subjects? As it is, they found that the "return of IRR ... led to low levels of test-specific distress and uncertainty among carriers," and that "at both (before and 6 months after disclosure), carriers reported feeling sad more often than noncarriers" $(p=0.002)$. And this with only 15 carriers from 5 families. A larger study or one that continued longer than 6 months might have found more troubling responses, including, e.g., suicide or suicidal ideation. "It is virtually impossible," Bruno [12] writes regarding surveillance for pancreatic abnormalities, "for a single institution to produce something that is scientifically worthwhile ... The time has now come to join forces and design methodically sound prospective international multicenter research programs to unravel the potential of screening for pancreatic cancer." To that we would like to add: and to examine responsibly and with sufficient statistical power the responses of human subjects to learning their research results."

As more germline mutations associated with cancer and other diseases are discovered in the course of research, the temptation will grow for investigators to inform subjects whom they identify as carriers before the magnitude of the lifetime risk, effective actionability, and behavioral responses have been established in national and international collaborations. It is up to investigators to scrupulously adhere to the criteria for the return of IRR that have already been established. Publishing papers that do not do so will only encourage more poor research. We have attempted to point out the problems, using the paper by Zhu et al. [1] as an example. We will no longer accept such papers. We hope other journals will follow our lead.

\section{Disclosure Statement}

The authors have no conflicts of interest to declare.
Holtzman/Probst-Hensch 


\section{References}

1 Zhu X, Leof ER, Chaffee KG, McCormick JB, Petersen GM, Radecki Breitkopf C. Psychological impact of learning CDKN2A variant status as a genetic research result. Public Health Genomics. 2018. DOI: $10.1159 / 000496556$.

2 https://seer.cancer.gov/statfacts/html/pancreas.html

$3 \mathrm{Hu}$ C, Hart SN, Polley EC, Gnanaolivu R, Shimelis $\mathrm{H}$, Lee KY, et al. Association Between Inherited Germline Mutations in Cancer Predisposition Genes and Risk of Pancreatic Cancer. JAMA. 2018 Jun;319(23):2401-9.

4 Beskow LM, Burke W. Offering individual genetic research results: context matters. Sci Transl Med. 2010 Jun;2(38):38cm20.

5 Jarvik GP, Amendola LM, Berg JS, Brothers K, Clayton EW, Chung W, et al.; eMERGE ActROR Committee and CERC Committee; CSER Act-ROR Working Group. Return of genomic results to research participants: the floor, the ceiling, and the choices in between. Am J Hum Genet. 2014 Jun;94(6):818-26.

6 Fabsitz RR, McGuire A, Sharp RR, Puggal M, Beskow LM, Biesecker LG, et al.; National Heart, Lung, and Blood Institute working group. Ethical and practical guidelines for reporting genetic research results to study participants: updated guidelines from a National Heart, Lung, and Blood Institute working group. Circ Cardiovasc Genet. 2010 Dec;3(6): $574-80$.

7 NM_000077.4(CDKN2A):c.47 TG (p.Leu16Arg). https://wwwncbinlmnihgov/ clinvar/variation/219815/.2018.
8 Marks D, Horn IP, Hogenson TL, et al. Reducing protein stability underlies the protumoral function of L16R(47T $[\{\mathrm{GT}\}] \mathrm{G}) \mathrm{CDK}-$ N2A, a mutation associated with familial pancreatic cancer. Paper presented at: American Assocaition for Cancer Research (AACR) Special Conference: Pancreatic Cancer: Advances in Science and Clinical Care; September, 2018; Boston, MA. 2018.

9 McWilliams RR, Wieben ED, Rabe KG, Pedersen KS, Wu Y, Sicotte H, et al. Prevalence of CDKN2A mutations in pancreatic cancer patients: implications for genetic counseling. Eur J Hum Genet. 2011 Apr;19(4):472-8.

10 de Snoo FA, Bishop DT, Bergman W, van Leeuwen I, van der Drift C, van Nieuwpoort $\mathrm{FA}$, et al. Increased risk of cancer other than melanoma in CDKN2A founder mutation (p16-Leiden)-positive melanoma families. Clin Cancer Res. 2008 Nov;14(21):7151-7.

11 Begg CB, Orlow I, Hummer AJ, Armstrong BK, Kricker A, Marrett LD, et al.; Genes Environment and Melanoma Study Group. Lifetime risk of melanoma in CDKN2A mutation carriers in a population-based sample. J Nat Cancer Inst. 2005 Oct;97(20):1507-15.

12 Bruno MJ. Pancreatic cancer screening in high-risk individuals: ready for prime time? Gastrointest Endosc. 2018 Jun;87(6):1451-3.
13 Vasen H, Ibrahim I, Ponce CG, Slater EP, Matthäi E, Carrato A, et al. Benefit of Surveillance for Pancreatic Cancer in High-Risk Individuals: Outcome of Long-Term Prospective Follow-Up Studies From Three European Expert Centers. J Clin Oncol. 2016 Jun;34(17): 2010-9.

14 Austin J. The effect of genetic test-based risk information on behavioral outcomes: A critical examination of failed trials and a call to action. Am J Med Genet A. 2015 Dec; 167A(12):2913-5.

15 Canto MI, Harinck F, Hruban RH, Offerhaus GJ, Poley JW, Kamel I, et al.; International Cancer of Pancreas Screening (CAPS) Consortium. International Cancer of the Pancreas Screening (CAPS) Consortium summit on the management of patients with increased risk for familial pancreatic cancer. Gut. 2013 Mar;62(3):339-47.

16 Syngal S, Brand RE, Church JM, Giardiello FM, Hampel HL, Burt RW; American College of Gastroenterology. ACG clinical guideline: genetic testing and management of hereditary gastrointestinal cancer syndromes. Am J Gastroenterol. $2015 \mathrm{Feb} ; 110(2): 223-62$

17 National Comprehensive Cancer Network Pancreatic Adenocarcinoma. NCCN Clinical Practice Guidelines in Oncology. Version 3. 2017.

18 DaVee T, Coronel E, Papafragkakis C, Thaiudom S, Lanke G, Chakinala RC, et al. Pancreatic cancer screening in high-risk individuals with germline genetic mutations. Gastrointest Endosc. 2018 Jun;87(6):1443-50. 